\title{
Immunocytochemical Localization of Rhodopsin-Like Immunoreactivity in the Outer Segments of the Rods and Single Cones of Chick Retina
}

\author{
Masasuke Araki, Kenji Watanabe* and Kunio Yasuda** \\ Department of Anatomy, Jichi Medical School, Tochigi 329-04, *Department \\ of Anatomy, Fukui Medical School, Fukui 910-11 and **Department of Bio- \\ physics, Faculty of Science, Kyoto University, Kyoto 606, Japan
}

\begin{abstract}
Photoreceptor cells in chick retina consist of a rod and five types of cones. Immunocytochemical techniques have pinpointed rhodopsinlike immunoreactivity in the outer segments of some single cones as well as in rods. The antibody used in our study was raised against bovine rhodopsin purified by SDS-polyacrylamide gel electrophoresis. No rhodopsin-like immunoreactivity was found in the principal and accessory cone. Epon-embedded, semi-thin sections also were treated with potassium hydroxide to remove epoxy resin and then subjected to immunoreaction with the antibody. With this method the same results were obtained repeatedly, and the possibility of staining failure in double cones and some single cones due to insufficient permeability was avoided.

Electron microscopy revealed that the oil droplets of stained single cones are slightly smaller and are located in a more vitreal position than those of unstained single cones. The stained single cones are presumed to be types II and III single cones. In the inner segment, especially in the Golgi region and the rER, no staining was seen. Only slight staining was found in the connecting cilium and in the small vesicular or granular structure between the oil droplet and the plasma membrane facing the heavily stained outer segment. This suggests that opsin is incorporated into the plasma membrane in the distal portion of the inner segment.
\end{abstract}

Extensive reports of morphological diversity in the shape and size of vertebrate retina photoreceptor cells have been made. Such morphological differentiation as various types of rods and cones is considered to be related to differences in the spectral sensitivities of receptor cells. The electrophysiological intracellular recording in single cones of carp retina is one such example (22). Biochemically, two classes of glycoproteins have been identified as visual pigments, rhodopsin as a rod pigment and iodopsin as a cone pigment (26).

$\left[{ }^{3} \mathrm{H}\right]$ Fucose labeling of the three types of cones in goldfish retina showed quantitative differences on electron microscopic autoradiography, evidence of the specialization of these structures (4). Immunohistochemical detection of rhodopsin in frog photoreceptor cells at the electron microscopic level has contributed much to our general understanding of how different receptor cells operate (17). It also has 
shown that there is rhodopsin transport from the synthetic site in the inner segment to the disk membrane of the outer segment.

The fine structure of chick retina photoreceptors has been described in detail. They have been shown to consist of one rod and five different types of cones $(14,15)$ but their function is not yet understood. Determination of the visual pigments in receptors is essential to an understanding of their functions. We here describe immunohistochemical detection of the localization of rhodopsin in chick retina based on the improved method developed by Kimura et al. (9). This method allows us to distinguish each type of receptor at the electron microscopic level and showed that rhodopsin-like immunoreactivity was localized in the outer segments of rods as well as in certain types of single cones. Results are discussed in relation to the colour vision of the chick.

\section{MATERIALS AND METHODS}

Immunohistochemistry. Chicks were maintained under cycled light (9 a.m. to 7 pmm.). Eye balls from 7- to 10-day-old chicks were enucleated immediately after decapitation between 3 and 5 p.m. and were cut through at the equatorial line with a razor blade. The posterior central portion was immersed in Fixative I for 30 min at $4{ }^{\circ} \mathrm{C}$ and then fixed in Fixative II for $48 \mathrm{~h}$. Fixative I contained $2 \%$ paraformaldehyde, $0.2 \%$ picric acid and $0.2 \%$ glutaraldehyde in $0.1 \mathrm{M}$ phosphate buffer ( $\mathrm{pH} 7.3$ ). Fixative II contained $2 \%$ paraformaldehyde and $0.2 \%$ picric acid in the same buffer. The tissues then were treated by the procedure of Kimura et al. (9) with some modifications. Fixed tissue was washed with $15 \%$ sucrose in the same buffer, then $20-\mu \mathrm{m}$ sections were cut with a freezing microtome for light microscopy and $50-\mu \mathrm{m}$ sections with a vibratome for electron microscopy. These cut sections were treated with $0.2 \%$ Triton X-100 diluted with PBS(PBS-Triton) for 4 days at $4^{\circ} \mathrm{C}$. Anti-opsin serum was obtained by immunizing rabbits with bovine rhodopsin that had been purified by SDS-polyacrylamide gel electrophoresis according to Papermaster et al. (16). The sample gave a single band after Western blotting onto a nitrocellulose sheet to which retinal proteins had been transferred from the SDS-polyacrylamide gel (2). For immunostaining, sections first were incubated in $2 \%$ normal calf serum for $30 \mathrm{~min}$ at room temperature, then after being washed three times with PBS-Triton, they were incubated for 3 days at $4^{\circ} \mathrm{C}$ in anti-opsin serum diluted $1: 400$ with PBS-Triton.

After further washing, the sections were incubated in porcine anti-rabbit $\mathrm{IgG}$, washed thoroughly then incubated in the rabbit peroxidase anti-peroxidase complex. Peroxidase activity was monitered by the diaminobenzidine method. As the control, nonimmunized rabbit serum was used in place of anti-opsin serum. Semi-thin sections for light microscopy also were cut from immunoreacted vibratome sections embedded in epoxy resin.

As the immunoreaction in the receptor cells seemed to take place 6 to $7 \mu \mathrm{m}$ below the surface of the vibratome sections, it is possible that the limited penetration of immunoglobulin might affect immunological results. To eliminate this possibility, $1-\mu \mathrm{m}$ epon-embedded sections were put through the immunoreaction. For this purpose, the whole eyes were fixed in Fixative I for $30 \mathrm{~min}$ at $4^{\circ} \mathrm{C}$, then washed with the same buffer containing $15 \%$ sucrose, dehydrated, and embedded in epoxy resin without post-fixation in osmium tetroxide. Semithin $1-\mu \mathrm{m}$ sections were placed on slide glasses, after which the resin was removed by immensing the samples in a supernatant solution of saturated potassium hydroxide in absolute ethanol (8). After washing them, the sections were incubated for $30 \mathrm{~min}$ at room temperature 
in anti-opsin serum diluted $1: 50$ with PBS-Triton. The sections then were processed by the PAP method described above.

\section{RESULTS}

Fine structure in chick photoreceptor cells. The fine structure in and types of chick retina receptors have been studied intensively by electron microscopy $(14,15)$. There are double and single cones, which can be distinguished from rods by the presence of oil droplets at the scleral end of their inner segments (Fig. 1). Each double cone is comprised of a principal and an accessory cone which lie against each other. Single cones are classified as types I, II and III by the density, position and size of the oil droplet. A paraboloid lies vitreal to an ellipsoid in the inner segments of rods as well as in the accessory cone. The accessory cone has a dense granular vesicle instead of an oil droplet. Because the method we used for fixation in our immunohistochemistry study differs so much from that used in previous studies, not all of the detailed features shown in Fig. 1. could be applied. Therefore, we have paied most attention to the position and size of the oil droplets.

Light microscopy localization of opsin in chick retina. Specific staining was found exclusively in the outer segments of receptors (Fig. 2). Because the chicks had been in a light-adapted environment, pigment epithelial granules surrounded the outer

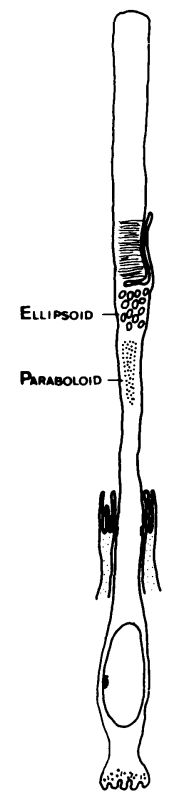

A

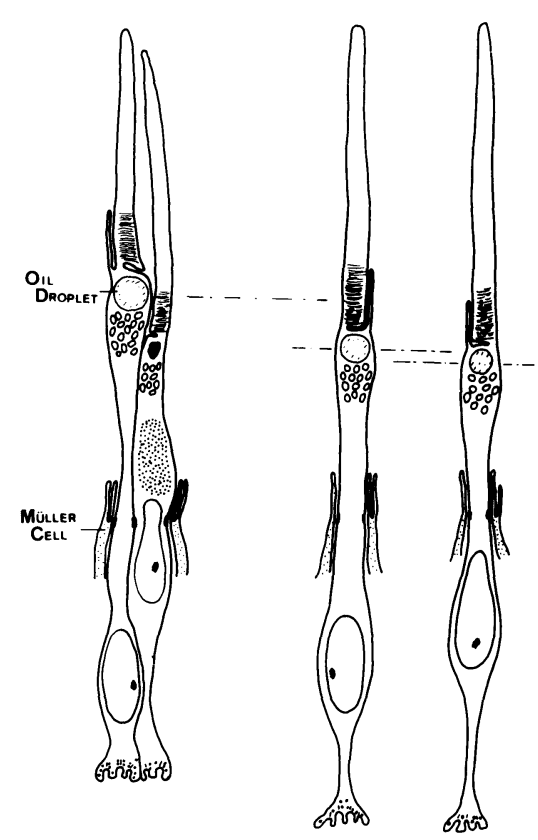

B

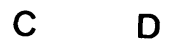

Fig. 1. Drawings of chick retina receptor types. A: rod, B: doublecone comprised of a principal (left) and accessory cone (right), C: single cone type I, D: type II and III single cone. Types II and III can be distinguished onle by the density of their oil droplets. This figure is cited from Morris and Shorey (1967) and was modified according to Morris (1970) and our present observations. 
segments, which made it difficult to show the entire length of the outer segment. The inner segments appeared free of any reaction product. In the semi-thin sections prepared from the immunoreacted vibratome sections, only a few components in the outer segments showed any of the reaction product (Fig. 3A). Oil droplets in the stained outer segments always occurred toward vitreal sites. Outer segments whose oil droplets were in more scleral positions were not stained. When semi-thin sections reacted with anti-opsin serum after being placed on slide glasses and having the epoxy resin removed to avoid the possibility of uneven penetration of antiserum, results were the same as described above (Fig. 3B).

Electron microscopy of chick retina. With the electron microscope, several types of receptor are clearly distinguishable. As indicated by light microscopy, the outer segment of principal cone never showed any reaction product (Fig. 4), neither did the outer segment of the accessory cone. The granular vesicle of the accessory cone was extracted and left one (occassionally two) large vacuole as remnants (Fig. 6). Intense reaction product, however, was found in the outer segments of some single cones (Figs. 5 and 6). We also noticed that the oil droplets in stained single cones were at slightly more vitreal positions and were smaller than those of neighboring unstained single cones, their density, however, was not always constant (Fig. 6). Our observations indicate that the outer segments of types II and III single cones are stained, whereas those of type I are unstained.

As for rods, immunostaining was found as expected in the outer segments (Fig. 7). In the preparation used the disc membranes of the rods often were destroyed, and only the rod plasma membranes remained. Intense staining was present on the plasma membrane and on the remaining disc membrane of the outer segments of rods.

The connecting cilium of the positive receptors often was stained less intensively than the outer segment, and no immunoreaction was found in the inner segments of positive receptors (Fig. 8). Some faint staining was present in the narrow portion of the cytoplasma between an oil droplet and the plasma membrane facing the outer segment. The reaction in this portion seemed to take place in granular bodies or tiny vesicles.

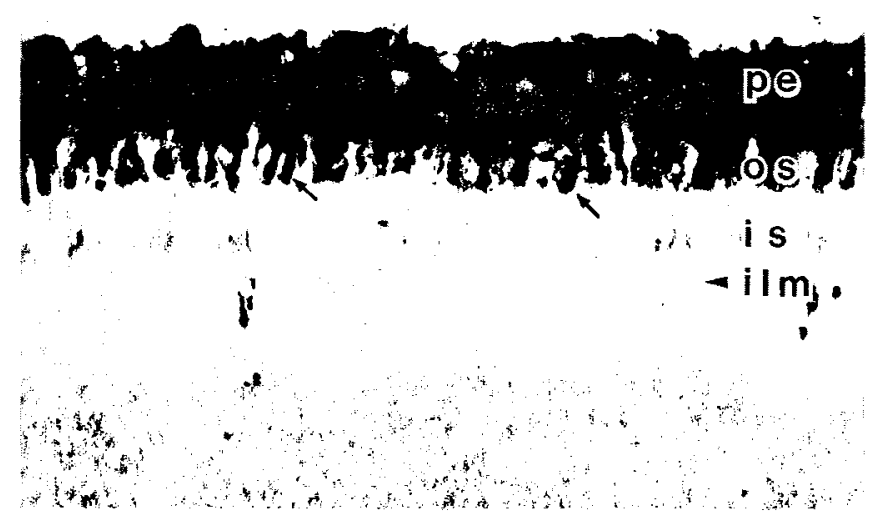

Fig. 2. Immunoreaction with a $20-\mu \mathrm{m}$ frozen section of 7 -day-old chick retina. The reaction is found only in the outer segment (arrows). pe: pigment epithelium, os: outer segment, is: inner segment, ilm: inner limiting membrane. $\times 560$. 


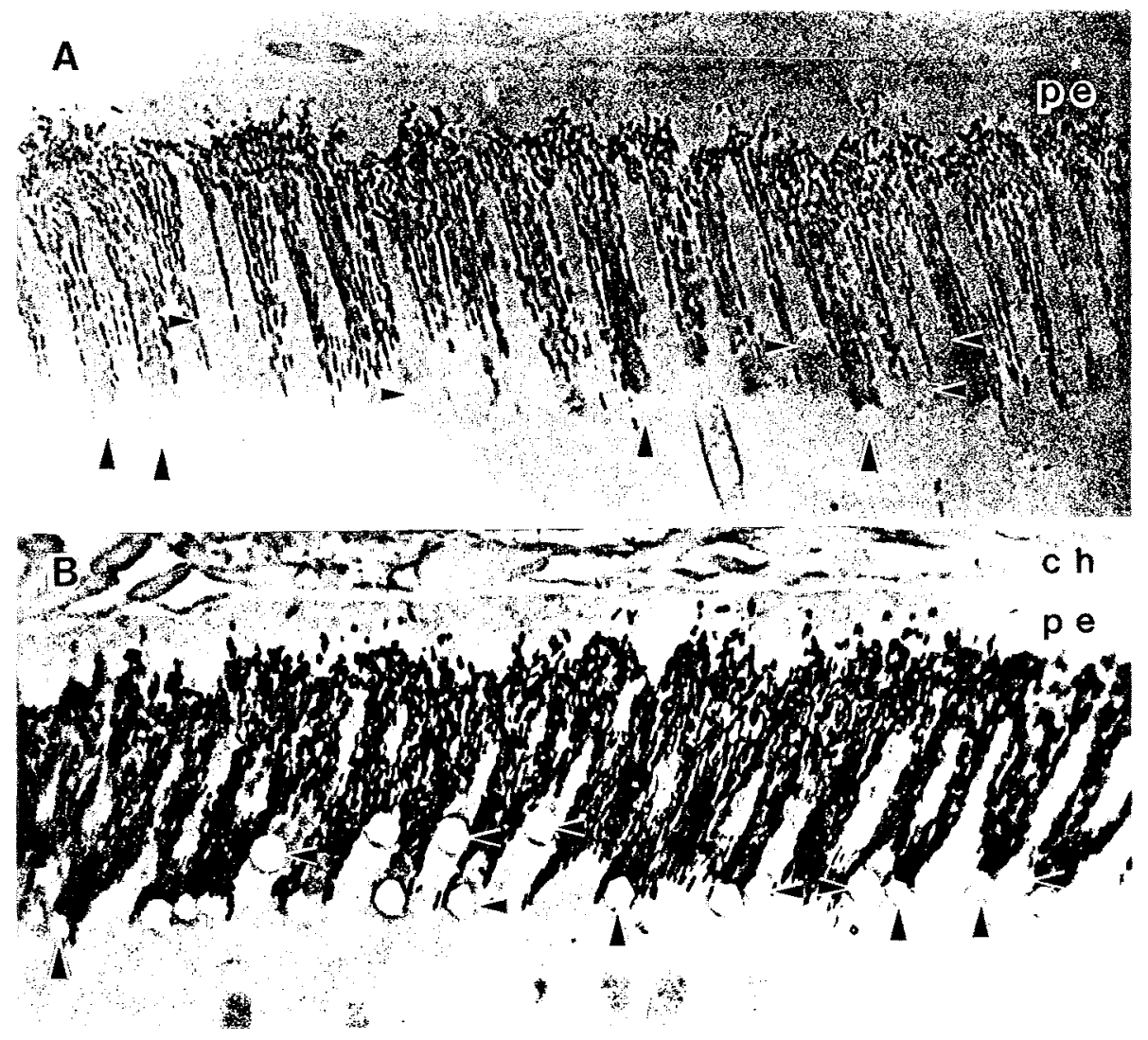

Fig. 3. Immunoreaction of epon-embedded, 1- $\mu \mathrm{m}$ sections from 7-day-old chick retina. (A) 50- $\mu \mathrm{m}$ thick vibratome sections first were treated for the immunoreaction, then after being embedded in epoxy resin, 1- $\mu \mathrm{m}$ semi-thin sections were made. Vertical arrowheads indicate oil droplets in cones whose outer segments are stained, whereas horizontal arrowheads indicate those of unstained outer segments. Oil droplets with vertical arrowheads often are present at a level (vitreal side) lower than those with horizontal arrowheads. These observations also are shown in (B). In (B), 1- $\mu \mathrm{m}$ sections were prepared from epon-embedded unsectioned retinas then were stained with anti-rhodopsin serum. $\times 1,100$.

\section{DISCUSSION}

Since the first report of Max Schultze (20), considerable controversy has existed regarding the morphological types of chick photoreceptor cells $(11,13)$. Fine structural observations made by Morris (14) showed that chick receptors consist of rods, double cones (each comprised of a principal and an accessory cone), and three types of single cones. Single cone classification has been based on differences in the electron density, position, and size of oil droplets. Of the three types, types II and III are distinguished only by a small difference in density in tangential sections as prepared by the strong fixation used by Morris (direct fixation in osmium tetroxide). These distributions have not been recognized in radial sections (15).

By our immunocytochemistry method we were able to distinguish two types of 


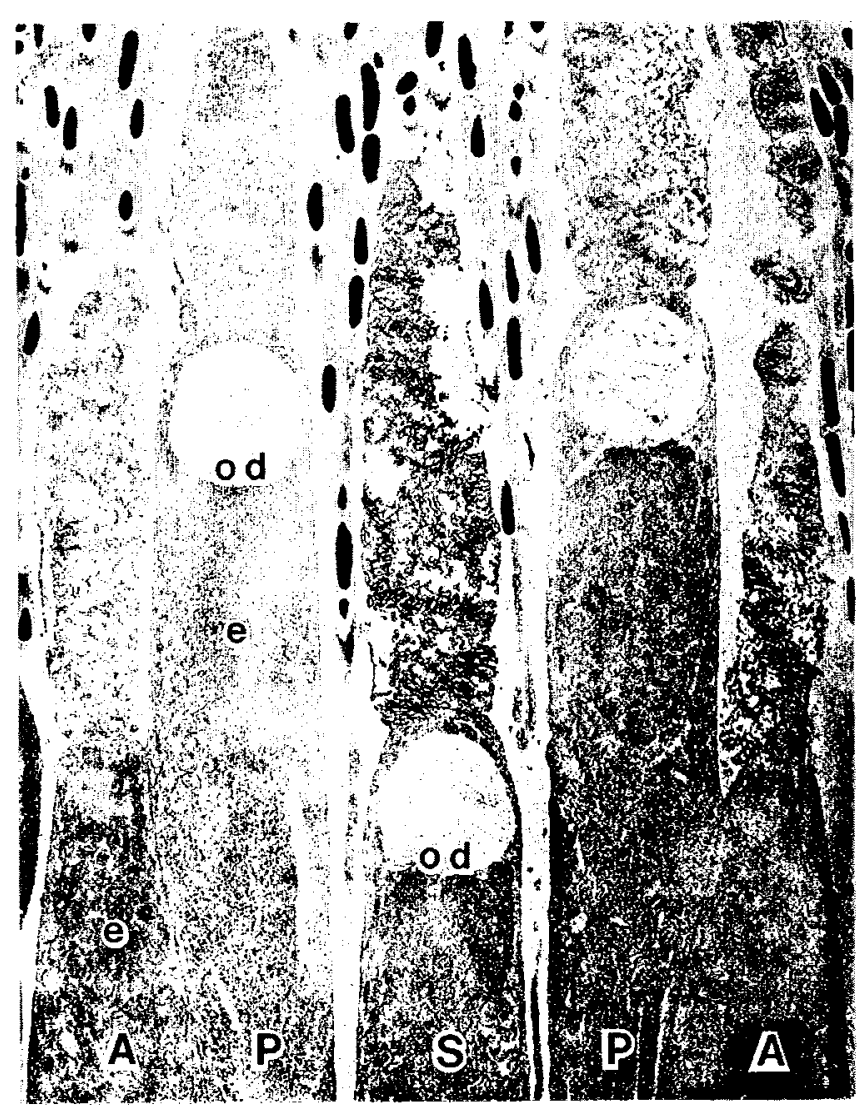

Fig. 4. A single cone (S) with stained outer segments lies between two double cones. Oil droplets (od) of the principal cones ( $p$ ) have appearances similar to the droplet in the single cone. No reaction was found in the outer segments of both the principal and accessory (A) cones. Without electron stain. e: ellipsoid. $\times 5,000$.

single cones; one with intense rhodopsin-like immunoreactivity in its outer segment and the other with none. We concluded that positive cells are types II and III and negative ones type I on the basis of the position and size of their oil droplets. The electron density of the oil droplets could not be used as a criterion because this feature was extremely labile with the weak fixation used for our immunocytochemical preparations. Oil droplets of negative single cones, however, appeared electronlucent, whereas those of most positive single cones seemed to have been extracted and only some amorphous remnants were present. Oil droplets of the principal cones were similar to those of the positive cones. These observations are further support for our

Fig. 5. Seven photoreceptor cells sectioned longitudinally. Of these, the three single stained cones are designated $\mathrm{Sp}$ (single cone-positive). The other three single cones which are not stained (Sn: single cone-negative), have oil droplets filled with very faint material that are in a more scleral location than the droplets of the neighboring stained single cones. An outer segment $(R)$ of the rod is surrounded by the plasma membrane and is stained faintly. p: paraboloid of the rod. Stained with uranyl acetate. $\times 4,700$. 


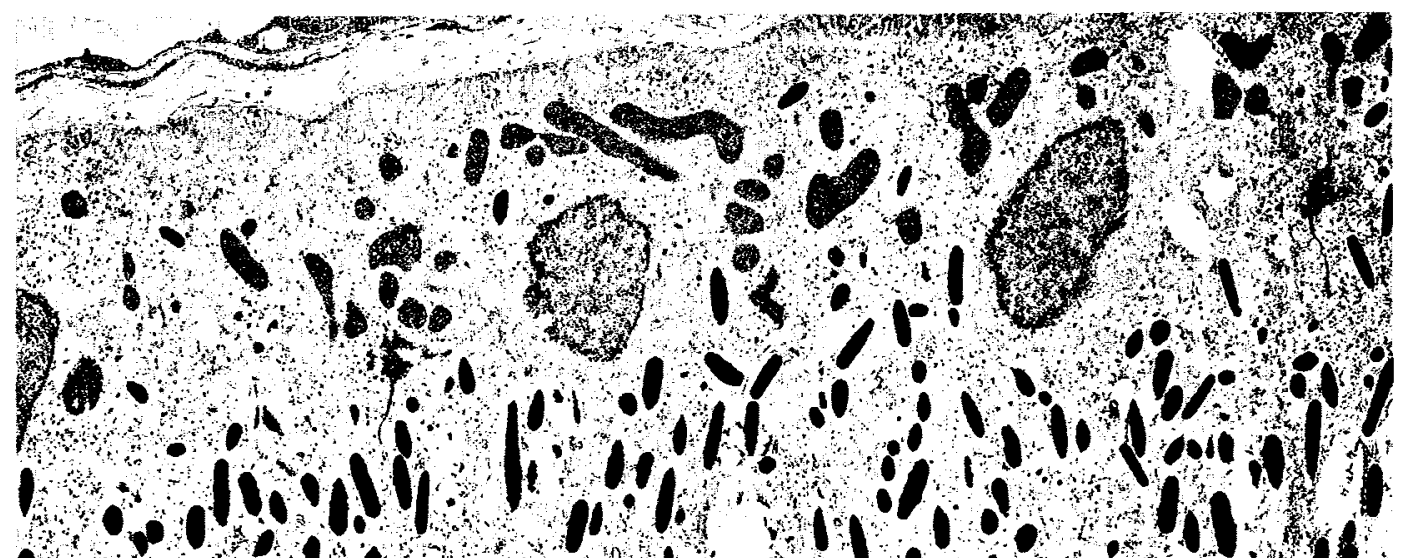

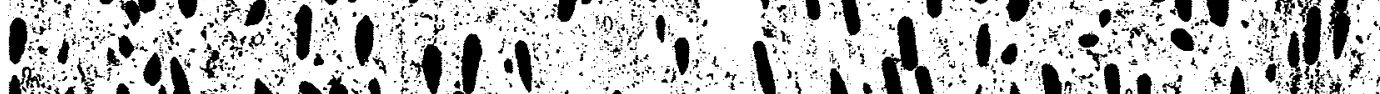

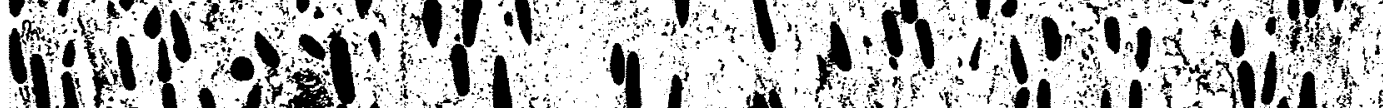

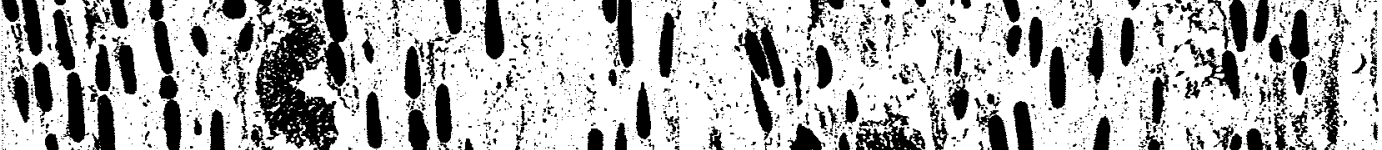

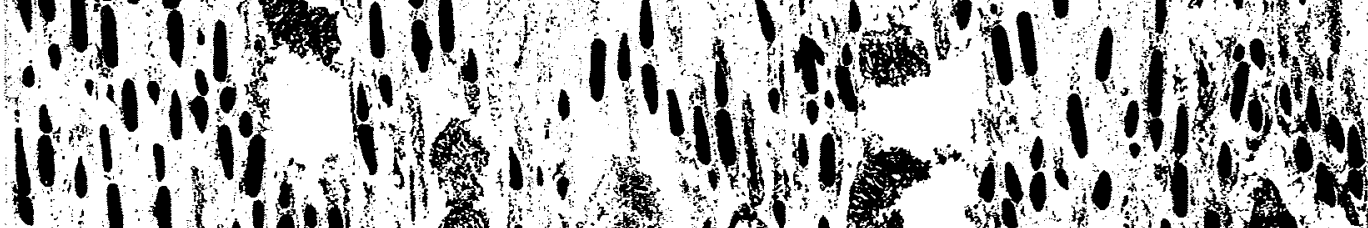

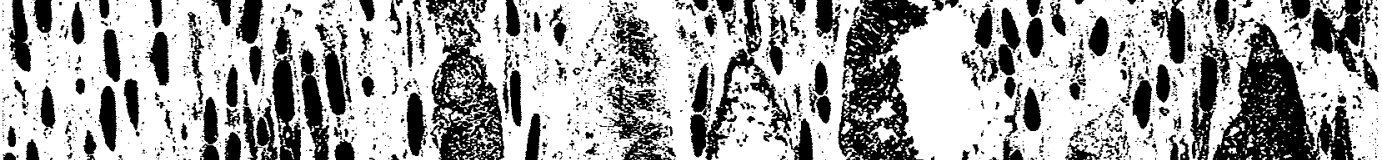

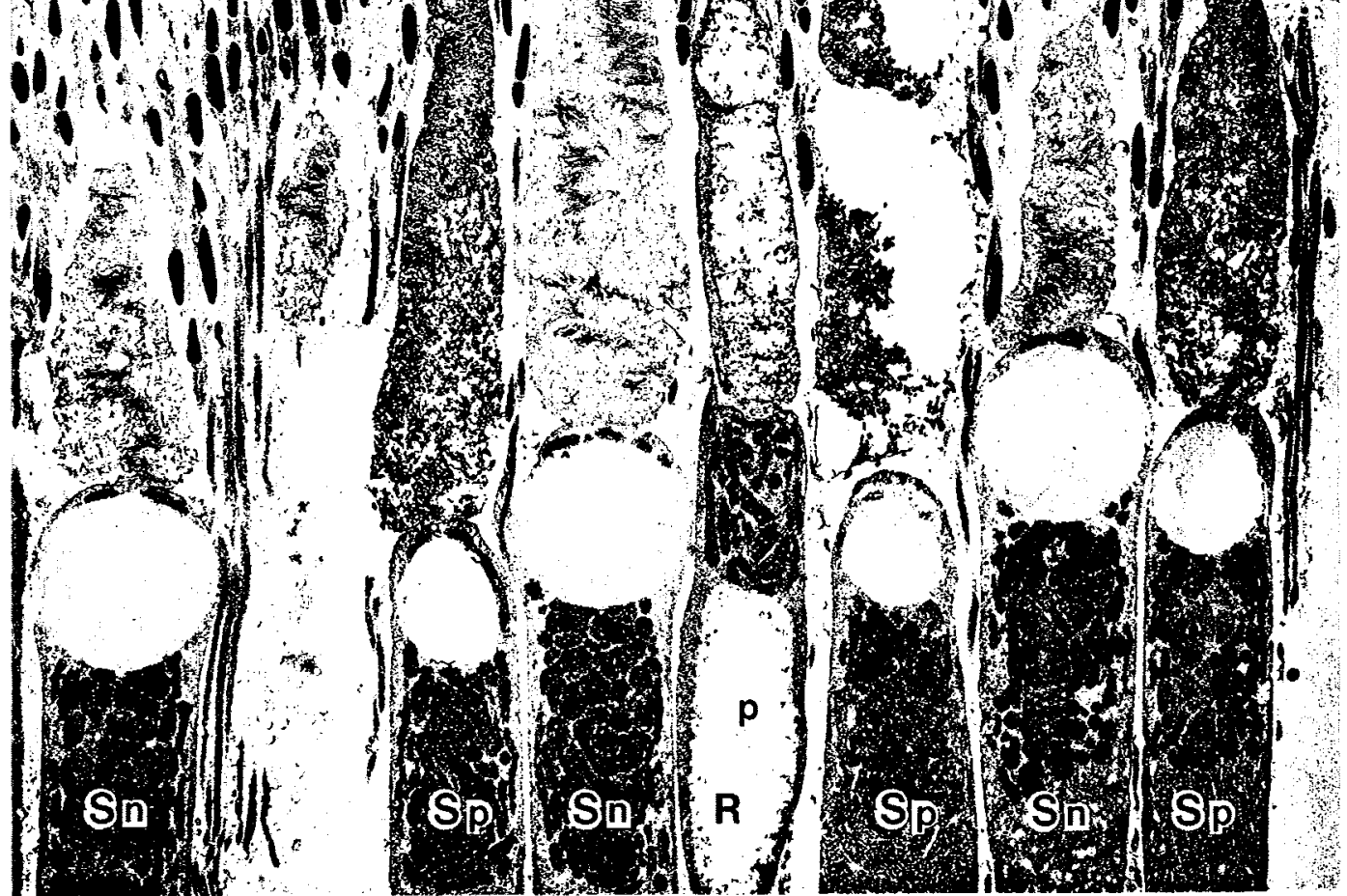




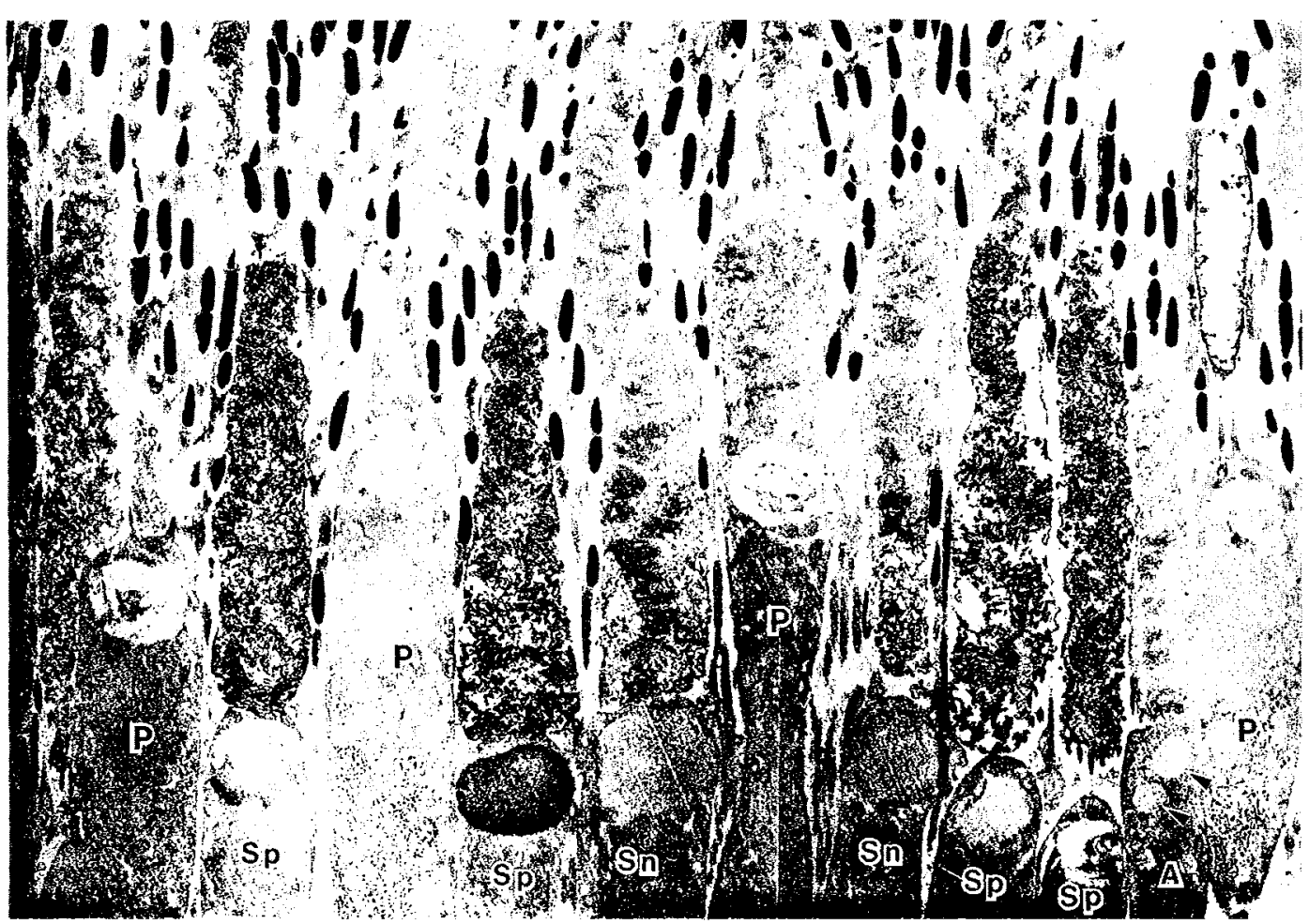

Fig. 6. In this figure, four stained single cones ( $\mathrm{Sp}$ ), and two unstained single cones (Sn) are present. There are also four principal cones (P). The characteristic features of the receptors in Fig. 4 and 5 are confirmed in this figure. The oil droplets of the stained single cones, however, vary in density. In the inner segment of the accessory cone (A) there are two large vacuoles (arrowheads). $\times 4,700$.

conclusion that a difference in immunoreactivity corresponds to a difference in single cone types. Further diversity in the appearance of oil droplets in positive cones might be related to differences between types II and IJI, but no direct evidence is yet available.

Rhodopsin is the major glycoprotein in the outer segments of the rods of many vertebrate retinas. Phylogenetically, the biochemical and photochemical properties of rhodopsin are nearly constant $(5,6)$. Its antigenecity also has been shown to be common to bovine, rat and frog retinas $(7,17)$. By using a highly specific anti-bovine opsin serum which crossreacts with rat rods, we here have shown that chick rhodopsin also shares antigenic determinants with bovine opsin.

An unexpected finding was that intense immunostaining occurred in the outer segments not only of rods but of types II and III single cones as well. Although this does not necessarily mean that types II and III single cones contain a visual pigment identical to rhodopsin, it can be said that two immunologically different classes of visual pigments are present in cones.

Two types of visual pigments are known in chick retina, rhodopsin and iodopsin. Iodopsin is considered a single pigment microphotometrically as well as biochemically (10). Therefore, it is reasonable that types II and III single cones would contain rhodopsin rather than iodopsin, but more detailed analyses of chick visual pigments 


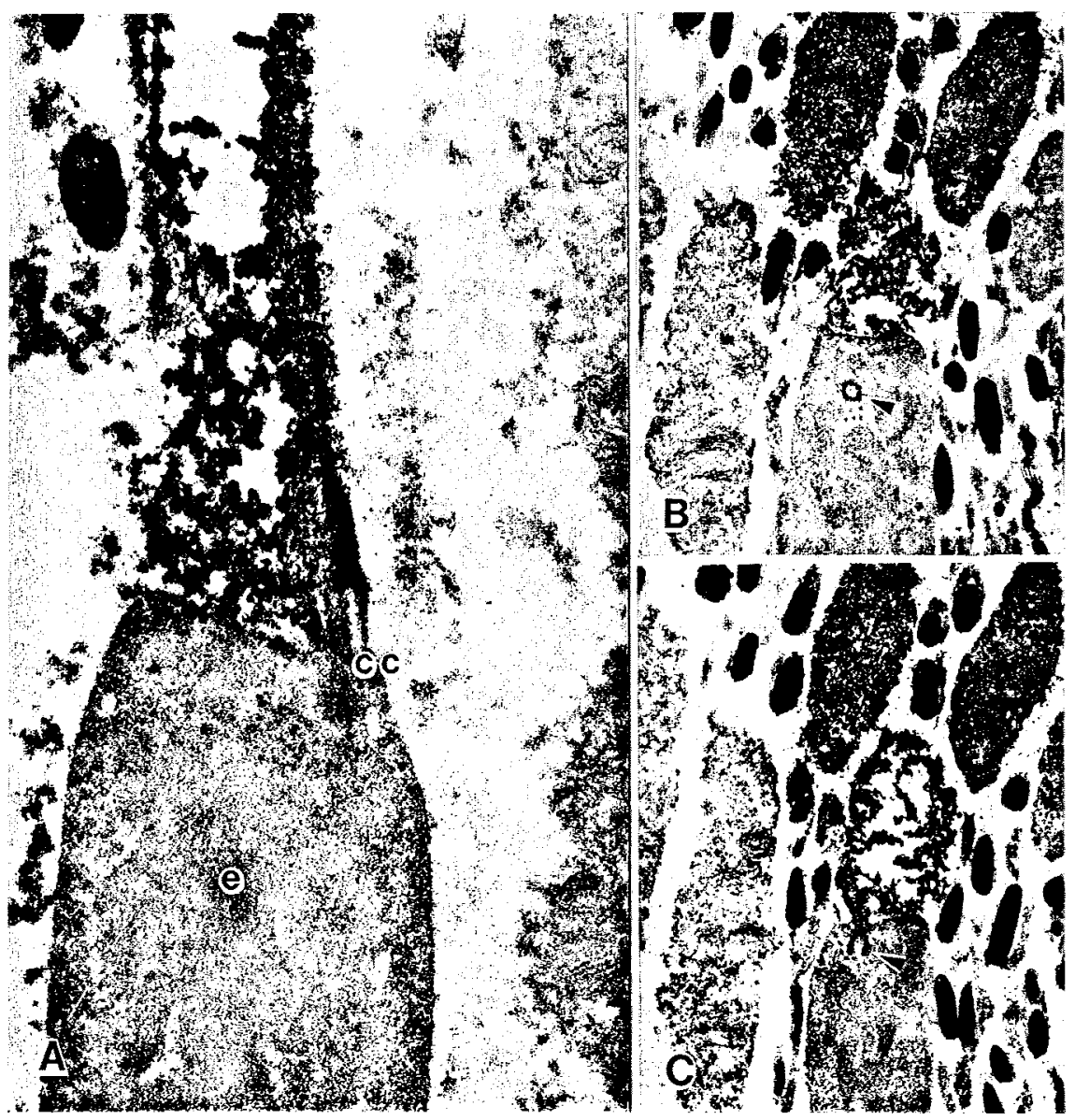

Fig. 7. Immunoreaction in the outer segments of a rod. (A) The disc membranes have been destroyed, and the plasma membrane of the inner segment seems to be free of the reaction. e: ellipsoid, cc: connecting cilium. $\times 20,000$. (B) and (C) show serial sections of the same rod. No oil droplets or vesicular structures are present. Arrowheads indicate the basal bodies of the connecting cilium. The two stained outer segments of single cones in the upper parts of the photographs $(B, C)$ have been cut obliquely. $\times 8,000$. With no electron staining.

is required to validate this supposition. Bowmaker and Knowles (3), in their microspectrophotometric study, suggested that the chick rod receptor contains a rhodopsin of $\lambda \max 506 \mathrm{~nm}$ and that certain types of single cones contain a pigment of $\lambda$ max $497 \mathrm{~nm}$. Possibly, this latter visual pigment is immunologically similar to rhodopsin and crossreacts with anti-rhodopsin serum.

The chick retina is reported to have three colors of oil droplets; green, red, and yellowish, but some differences have been reported by different authors $(12,20,25)$. The color vision of the avian retina is believed to be due to the existence of these oil droplets. As a necessary consequence, even if only the visual pigment of a single cone is present, the cones will provide different signals for the spectral composition of incident light (19). 
It has been suggested that the oil droplet in the principal cone is green, and that droplets in single cones are red or yellowish (14). Our results suggest that types II and III single cones with rhodopsin $(\lambda \max , \mathrm{ca} .500 \mathrm{~nm})$ have yellowish oil droplets and type I has red droplets with iodopsin $(\lambda \max$, ca. $560 \mathrm{~nm})$. Our reasoning is as follows: If the opposite were the case, then injected light of $500 \mathrm{~nm}$ wavelength would be absorbed by the red oil droplet, and only a small amount would reach the visual pigment, rhodopsin. Obviously, it would be more favorable for the color vision of the chick if red oil droplets were combined with iodopsin and yellowish oil droplets with rhodopsin rather than to have a situation in which all the single cones contain only one visual pigment, iodopsin. Our speculations are consistent with the results of Papermaster et al. (17) that anti-bovine opsin serum reacts preferentially with red rods rather than with green rods.

We detected no positive staining in the rER and Golgi complex of the inner segments with our immunochemical method. Because opsin is synthesized continuously in inner segments $(16,27)$, there are two possible explanations for the absence of a reaction in the inner segment: One is that antigenicity changes when the opsin molecules are incorporated into the outer segments. This does not seem to be the case because biochemical studies of frog retina have shown there is no modofication of the protein portion of opsin during transfer of the molecule (16). The alternative is that, since the synthetic rate of opsin is low and since the product is transferred to the outer segment within a short period (27), it may be difficult to detect such small

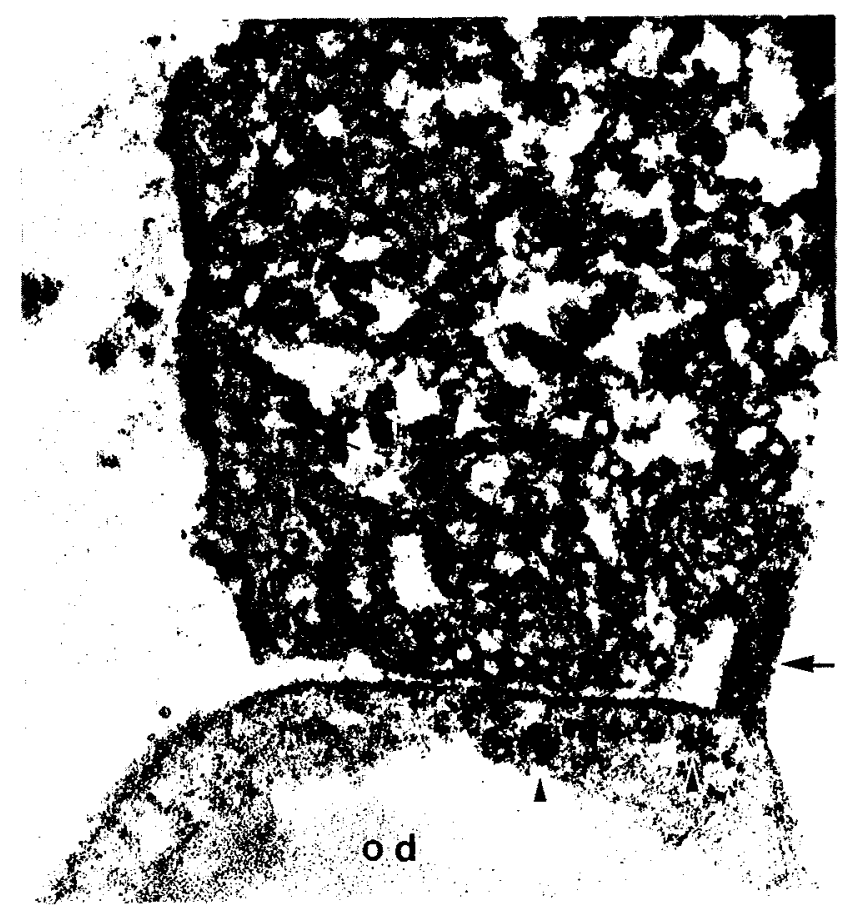

Fig. 8. High magnification of the basal portion of a stained outer segment of a single cone. The disc appears vesicular or tubulous. Some granular structures seem to be stained (arrowheads) in the distal portion of the inner segement of the cytoplasm between the oil droplet (od) and plasma membrane. With no electron stain. $\times 37,000$. 
amounts of antigen with our method. The presence of reaction product in the connecting cilium and in the small granular or vesicular structures in the uppermost portion of the inner segment suggests that synthesized opsin is collected at this site then transferred to the base of the outer segment where new disc membranes are formed continuously by evagination of the plasma membrane (21). Observations made of the frog retinal rod are consistent with our findings $(1,18)$.

Acknowledgements. We thank Professor T. Saito, Department of Anatomy, Jichi Medical School, for his continuous support and valuable discussions, Professor P.L.McGeer, Department of Psychiatry, the University of British Columbia and Dr. D.I. dePomerai, Department of Zoology, the University of Nottingham, for reviewing the manuscript.

\section{REFERENCES}

1. ANDREWS, L.D. Freeze-fracture studies of vertebrate photoreceptor membranes. in The Structure of the Eye, ed. J.G. Hollyfield, Elsevier, New York, pp. 11-24, 1982

2. ARAKI, M. Immunohistochemical study of photoreceptor cell differentiation of the chick retina. Cell Struct. Funct. 7, 437, 1982

3. Bowmaker, J.K. and A. Knowles. The visual pigments and oil droplets of the chick retina. Vision Res. 17, 755-764, 1977

4. Bunt, A.H. and J.C. SAARI. Fucosylated protein of retinal cone photoreceptor outer segments: Morphological and biochemical analysis. J. Cell Biol. 92, 269-276, 1982

5. Dartnall, H.J.A. and J.N. Lythgoe. The spectral clustering of visual pigments. Vision Res. 5, 81-100, 1965

6. Heller, J. Comparative study of a membrane protein. Characterization of bovine, rat, and frog visual pigments. Biochem. 8, 675-679, 1969

7. JAN, L.Y. and J.-P. REVEL. Ultrastructural localization of rhodopsin in the vertebrate retina. J. Cell Biol. 62, 257-273, 1974

8. Imai, Y., A. Sue, and A. Yamaguchi. A removing method of the resin from Epoxy-embedded sections for light microscopy. J. Electron Micro. 17, 85-84, 1968

9. Kimura, H., H.J. Peng, P.L. McGeer and E.G. McGeer. The central cholinergic system studied by choline acetyltransferase immunohistochemistry in the cat. J. Comp. Neurol. 200, 151-202, 1982

10. King-Smith, P.E. Atsorption spectra and function of the colored oil drops in the pigeon retina. Vision Res. 9, 1391-1399, 1969

11. Meyer, D.B. and T.C. CoOper. The visual cells of the chick as revealed by phase contrast microscopy. Am. J. Anat. 118, 723-734, 1966

12. Meyer, D.B., T.G. CoOper and C. Gernez. Retinal oil droplet. in The Structure of the Eye, Symposium, vol. 2, ed. by J.W. Rohen, pp. 521-533, Schattauer-Verlag, Stuttgart, 1965

13. MeYer, D.B. and H.C. MaY. The topographical distribution of rods and cones in the adult chicken retina. Exp. Eye Res. 17, 347-355, 1973

14. Morris, V.B. Symmetry in a receptor mosaic demonstrated in the chick from the frequencies, spacing and arrangement of the types of retinal receptor. J. Comp. Neur., 140, 359-398, 1970

15. Morris, V.B. and C.D. ShoreY. An electron microscope study of types of receptor in the chick retina. J. Comp. Neurl. 129, 313-340, 1967

16. Papermaster, D.S., C.A. Converse and J. SiU. Membrane biosynthesis in the frog retina: opsin transport in the photoreceptor cell. Biochem. 14, 1343-1352, 1975

17. Papermaster, D.S., M.A. Schneider and J.P. Kraehenbuhl. Immunocytochemical localization of opsin in outer segments and Golgi zones of frog photoreceptor cells. J. Cell Biol. 77, 196-210, 1978

18. Peters, K.-R., G.E. Palade, B.G. Schneider and D.S. Papermaster. Fine structure of a periciliary ridge complex of frog retinal rod cells revealed by ultrahigh resolution scanning electron microscopy. J. Cell Biol. 96, 265-276, 1983 
19. Rodiek, R.W. The Vertebrate Retina. W.H. Freeman and Company. San Francisco, pp. 248259, 1973

20 Schultze, M. Ueber Stäbchen und Zapfen der Retina. Arch. Mikr. Anat. 8, 248, 1867

21. Steinberg, R.H., S.K. Fisher and D.H. Anderson. Disc morphogenesis in vertebrate photoreceptors. J. Comp. Neur. 190, 501-518, 1980

22. Tomita, T., A. Kaneko, M. Murakami, and E.L. Pautler. Spectral response curves of single cones in the carp. Vision Res. 7, 519-531, 1967

23. Towbin, H., T. Staehelin and J. Gordon. Electrophoretic transfer of proteins from polyacrylamide gels to nitrocellulose sheets: Procedure and some applications. Proc. Natl. Acad. Sci. U.S.A. 76, 4350-4354, 1979

24. Wald, G., P.K. Brown and P. H. Smith. Iodopsin. J. Gen. Physiol., 38, 623-681, 1955

25. Walls, G.L. and H.D. JudD. The intra-ocular color filters of vertebrates. Br. J. Ophthal. 17, 641-675, 1933

26. Yoshizawa, T. In Handbook of Sensory Physiology, vol. VII/1, ed. H.J.A. Dartnall, Springerverlag, Berlin, pp. 143-179, 1972

27. Young, R.W. and B. Droz. The renewal of protein in retinal rods and cones. J. Cell Biol. 39, $169 \rightarrow 184,1968$

(Received for publication, December 20, 1983) 